\title{
Reconstructing Disruptive Life Events Using the RE-LIFE Questionnaire: Further Validation of the 'Narrative Meaning Making of Life Events' Model Using Multiple Mediation Analysis
}

\author{
Iris D. Hartog * \\ Radboud University, Nijmegen \\ Amsterdam UMC, University of Amsterdam \\ i.d.hartog@amsterdamumc.nl \\ Michael Scherer-Rath \\ Radboud University, Nijmegen \\ Tom H. Oreel \\ Amsterdam UMC, University of Amsterdam \\ Justine E. Netjes \\ Amsterdam UMc, University of Amsterdam \\ José P.S. Henriques \\ Amsterdam UMC, University of Amsterdam \\ Jorrit Lemkes \\ Amsterdam UMc, VU University, Amsterdam \\ Alexander Vonk \\ Amsterdam UMC, VU University, Amsterdam
}

Mirjam A.G. Sprangers

Amsterdam UMC, University of Amsterdam

Pythia T. Nieuwkerk

Amsterdam UMC, University of Amsterdam

* Corresponding author. 


\title{
Hanneke W.M. van Laarhoven
}

Amsterdam UMC, University of Amsterdam

\begin{abstract}
The theoretical model: 'Narrative meaning making and integration of life events' hypothesizes that life events such as falling ill may result in an 'experience of contingency'. Through narrative meaning making, this experience may be eventually integrated into patients' life stories, which, in turn, may enhance their quality of life. To contribute to our understanding of this existential dimension of falling ill and to further validate the theoretical model, we examined the relationships among the concepts assessed with the RE-LIFE questionnaire.

Two hypothesized mediation models were assessed using regression-based serial multiple mediation analysis. Model 1, assessing the influence of 'experience of contingency' on 'acknowledging', was significant and showed partial mediation by indirect influences through 'negative impact on life goals' and 'existential meaning'. Model 2, assessing the influence of 'experience of contingency' on 'quality of life', was also significant, with a full mediation by the variables 'negative impact on life goals', 'existential meaning' and 'acknowledging'. In conclusion, several hypothesized relationships within the theoretical model were confirmed. Narrative meaning making and integration significantly influence people's self-evaluation of their quality of life.
\end{abstract}

\section{Keywords}

experience of contingency - narrative meaning making - narrative integration - life goals - existential givens - illness - quality of life

\section{Introduction}

Falling seriously ill is known to have a large impact on a person's life. Naturally, illness may confront people with physical limitations, burdensome treatment and/or symptoms such as pain or fatigue, reducing their quality of life (QoL). However, illness may also confront people with the 'randomness of life', conflicting with life goals and expectations and invoking existential questions. This, in turn, may also influence the QoL patients perceive (Bolmsjö 2001, Fife 2002, Kruizinga et al. 2017).

To contribute to our understanding of this existential dimension of falling ill, we combined theories of narrative identity and contingency to develop the 
theoretical model: 'Narrative meaning making and integration of life events' (Hartog et al. 2017). This model hypothesizes that life events that conflict with a person's 'ultimate life goals' or worldview may result in an 'experience of contingency' (Wuchterl 2011, Kruizinga et al. 2017). The word 'contingent' means that something is 'neither necessary nor impossible' (Luhmann 1995), thus referring to the realm of the possible. Applied to humanity, contingency is a fact of life: everything, including our lives and the events that befall us, could have been otherwise (Makropoulos 1997). An 'experience of contingency' can be seen as a confrontation with this randomness, which confronts us with the limitations of our ability to comprehend the world and life. This confrontation can evoke a 'crisis of meaning', resulting from disruptive life events that initially cannot be interpreted in the context of one's life narrative and understanding of oneself and the world. Experiences of contingency may therefore lead to a fundamental reorientation of these understandings, through which the discrepancy with the existential meaning of the life event may be reduced (Park 2010). The meaning of the event evolves within this process of 'narrative meaning making'.

The idea of contingency implies that human beings are subject to randomness, but it also implies their creativity and ability to find ways of relating to the contingency of life events that befall them (Scherer-Rath 2013) and to find meaning (Frankl 1986). The ever-present possibility of meaning relates to our 'narrative intelligence' (Scherer-Rath 2016): our ability to integrate disruptive life events into our life narratives, giving them a meaningful place without dismissing the contingency of these life events.

In combining theories of narrative identity and contingency from narrative psychology, philosophy and religious studies, we propose a humanities approach to illness and other life events. This approach is complementary to psychological and medical approaches: it aims to further our understanding of the existential dimension of the same processes described in psychology and medical sciences. The theoretical basis of our approach converges with that of existential-psychotherapeutic approaches, which focus on finding and experiencing meaning in the face of the contingent nature of the very same meaning, instead of (reducing) psychopathological symptoms (Van Bruggen et al. 2013). The philosophical foundations of the existential-psychotherapeutic approaches are constituted by existentialism, specifically by the works of Yalom (1980) and Frankl (1988), theorizing our human 'will to meaning' as well as the 'existential givens' that are the horizon against which we search for this meaning. According to Yalom, the four most important existential givens are the inevitability of death, our existential social isolation, the lack of pre-given meaning in life ('meaninglessness') and, related to the latter, the inescapable freedom to choose in life (Yalom 1980). Especially disruptive life events such 


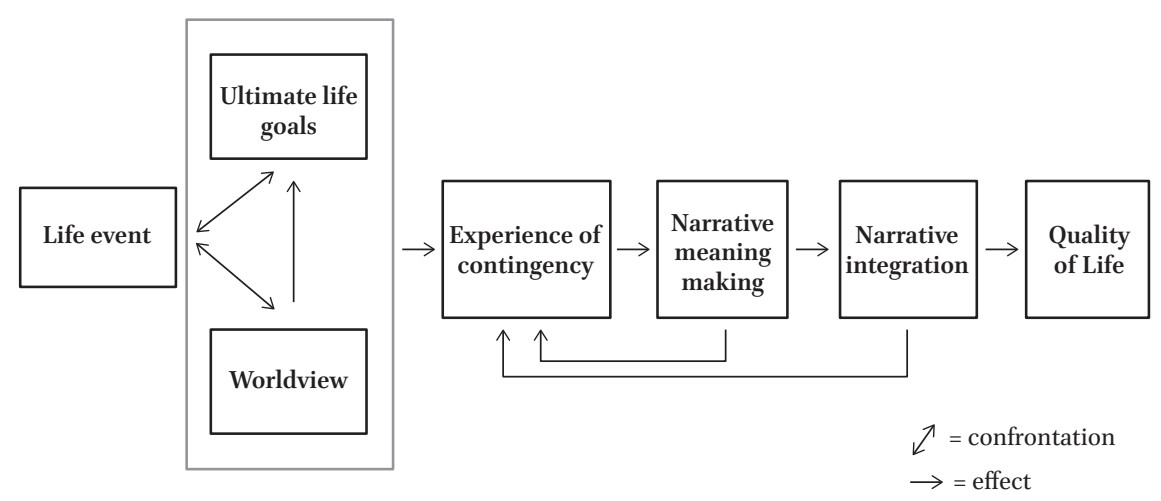

FIGURE 1 Theoretical model: narrative meaning making of life events HARTOG ET AL. 2017

as falling seriously ill confront us with these existential givens, shattering fundamental assumptions (Janoff-Bulman 2010) and meaningfulness but also opening up new possibilities and meanings. Our approach emphasizes both aspects of contingency: the boundaries of human action and comprehension as well as the meanings, creativity and action that are made possible by these boundaries.

Our theoretical model describes seven concepts and the relationships among them, see Figure 1. Falling ill and other life events may conflict with one's worldview and/or ultimate life goals: the goals that are of ultimate value to people. This conflict may result in an experience of contingency, followed by narrative meaning making: a process of reinterpretation in which the meaning of the life event may evolve. This process may lead to narrative integration to a greater or lesser extent: the integration of the event into the life narrative, influencing quality of life.

To enable empirical testing, this theoretical model was operationalized in the 'Reconstruction of Life Events questionnaire' ('RE-LIFE') (Hartog et al. 2017). This questionnaire starts with a request to draw a life line with positive and negative life events as high and low points. Consequently, respondents are asked to reflect on the meaning of their most unexpected negative life event and the experience of being diagnosed with a heart condition.

The questionnaire was tested in a large-scale longitudinal study on quality of life among heart patients. The psychometric properties and initial validation of the RE-LIFE questionnaire have been presented previously (Hartog et al., forthcoming). The aim of the present article is to examine the relationships among the concepts assessed with the RE-LIFE questionnaire, to further validate the theoretical model. 
Below, we describe the theoretical concepts of the model and their operationalization in the RE-LIFE questionnaire. This description will be confined to the conceptual distinctions that were empirically found, as the large-scale study showed that some of the identified scales were different than expected. A more elaborate description of the concepts, and the structure and items of the RE-LIFE questionnaire can be found in previously published articles (Hartog et al. 2017, Hartog et al., forthcoming).

Life event: According to narrative theory, life events are occurrences that a person considers meaningful for one's life as a whole (Ricoeur 1995, Frijda 2007). Unless one is convinced that all phenomena in the world can be attributed to religious or natural laws, which denies coincidence (Wuchterl 2019), all life events can be considered contingent because we can never fully control the course of our lives. However, unexpected negative life events, such as serious illness or other experiences of loss, may especially be experienced as 'boundary situations' (Jaspers 1925). They often confront people with the 'existential givens of life' such as mortality, vulnerability and the limits of our control and of our ability to understand the world (Park 2013, Vos 2015). In this study, only the responses concerning the experience of being diagnosed with a heart condition are presented, because we considered that to be more comparable among respondents than a self-chosen life event.

Worldview: Also referred to as 'outlook on life' or 'philosophy of life', worldview is broadly defined as the framework of conceptions, beliefs and attitudes by which people interpret reality, explicitly as well as implicitly (Kraft 2008, Schnell and Keenan 2011). In our study, we emphasize the aspect of the 'foundational reality' that a person's worldview refers to, which can be immanent or transcendent (Tillich 1963). Empirically, we found two types of worldview: 'absolute immanence' (relating to the human, intelligible world only) and 'transcendence' (relating to a transcendent dimension, i.e. 'something higher', which may be religious or non-religious) (Bucher 2014). The transcendent or 'spiritual' dimension provides people with a broader framework to interpret and integrate (disruptive) life events.

Ultimate life goals: Ultimate life goals are the goals or values giving ultimate meaning to people's lives, in the sense that they cannot be replaced by something else. We adopted the idea of psychologist Robert Emmons that all personal goals are not equally important. They are hierarchically ranked, and can be distinguished as 'ultimate' and 'instrumental' life goals (Emmons 1999, Baumeister and Vohs 2003). In the RE-LIFE questionnaire, we present fifteen potential ultimate life goals: health, happiness, autonomy, enjoyment, 
self-development, recognition, caring for others, caring for children, connecting with other people, teaching others, being a good person, love, doing what fits oneself, being of significance to others, and freedom. Respondents are asked how important each life goal is for them and how their heart condition positively or negatively influences their striving for each life goal at present.

Experience of contingency: We define an experience of contingency, in line with the field of religious studies, as a 'crisis of meaning' (Geertz and Banton 1966, Dalferth and Stoellger 2000, Wuchterl 2011, Scherer-Rath 2013). It may be the result of a life event that conflicts with one's worldview and/or ultimate life goals, which can be seen as a 'biographical disruption' or a 'breach of trust', necessitating a reinterpretation of the event (Bury 1982). Although people may differ in their inclination or need for narrative meaning making (Strawson 2015), we propose that the initial inability to make sense and meaning of a life event conflicts with our fundamental need for understanding, coherence and meaning (Frankl 1962, Frankl 1988, Baumeister 1991, Schnell 2009). The scale consists of items worded as metaphors often used by people when describing disruptive life events.

Narrative meaning making: Narrative meaning making is the process of reinterpretation of the event in the context of one's personal life narrative. The 'scope' of narrative meaning making refers to the scale or span of the meaning of the event. Events can have significance for the situation only (situational), one's life as a whole (existential) or for a transcendent dimension (spiritual). The latter two concepts were operationalized in two scales. The third concept, 'situational scope', was operationalized as low scores on both 'existential scope' and 'spiritual scope'.

Narrative integration: Narrative integration refers to the integration of the life event into one's personal life narrative and thus one's narrative identity, giving it a meaningful place. Our analysis of the RE-LIFE data indicated three scales: 'acknowledging', 'receiving new insights' and 'receiving'. In the 'acknowledging' mode, the event is not yet integrated but interpreted as a disruption of the life story, evoking existential questions and a search for ways to relate to the life event. ${ }^{1}$ The modes 'receiving new insights' and 'receiving' both indicate

1 Based on our analysis of interviews with terminally ill cancer patients (Kruizinga et al. 2017), our definition of the 'acknowledging' mode differs from Wuchterl's (2019) use of the concept. Wuchterl considers the judgement of an event to be contingent as part of his religiousphilosophical definition of contingency, just as 'an existential interest' and the need to 'deal' with the event. His definition of 'acknowledging' focuses on acknowledgement of the limits of reason in our attempts to understand the world and the events that befall us. In Wuchterl's vocabulary, acknowledging therefore also implies contemplating 'the possibility of an Other of Reason'. In our definition, 'acknowledging' implies 1) acknowledging the contingency of the event (the fact that it could also not have happened), 2) acknowledging the existential 
narrative integration, characterized by openness and receptivity for new insights and possibilities. The first emphasizes learning what's most important in life and the latter indicates happiness and embracing new possibilities that emerge from the life event. ${ }^{2}$

Quality of life: Quality of life (QoL) is a multidimensional construct widely used in research, its meaning depending on the field, context and aims of the research. In the medical sciences, QoL usually refers to the impact of disease or treatment on physical, mental and social functioning. Because our theoretical model revolves around the impact of illness on people's lives as a whole, we use a broad conception of QoL, i.e. 'overall QoL'. We adopted the definition of the World Health Organization (WHO): 'individuals' perception of their position in life in the context of the culture and value systems in which they live and in relation to their goals, expectations, standards and concerns' (wHO 1997).

Because the concepts of the theoretical model are configurated as a causal chain, a multiple mediation analysis is the most appropriate analysis to examine if the impact of the heart condition on quality of life is indeed (partly) explained by the variables belonging to the model of narrative meaning making.

To enable assessment of the theoretical model as a serial mediator model using the RE-LIFE data, a few adjustments were made to the model, see Figure 2. First, several background variables as assessed in our study were placed before the concepts of the theoretical model, as independent variables hypothesized to influence these concepts, directly or indirectly. These variables include medical variables (such as the type of cardiac intervention) that are hypothesized to influence how the life event of being diagnosed with a heart condition is experienced. Second, because a conflict between a life event and one's (often abstract and implicit) worldview is difficult to assess and is usually accompanied by a conflict with ultimate life goals, the RE-LIFE assesses the

impact of the event, and 3) the need to actively 'work' through one's interpretation of the event, searching for ways to relate to it.

2 The 'receiving' modes that we empirically found in our qualitative (Kruizinga et al. 2017) and quantitative (Hartog et al., forthcoming) research are inspired by Wuchterl's account of 'encountering' contingency, but are less religious in their meaning. In Wuchterl's definition, 'encounter' does not leave the 'content' of 'the Other beyond reason' open, but refers to the revelation of what exists beyond reason, thus entering the realm of religion (Wuchterl 2019). Our modes of 'receiving' share with this definition the openness for that which transcends our immanent framework, and a receptivity for new possibilities. However, the new insights and new possibilities that are 'received' are not necessarily the results of understanding or meeting something beyond our human world. 


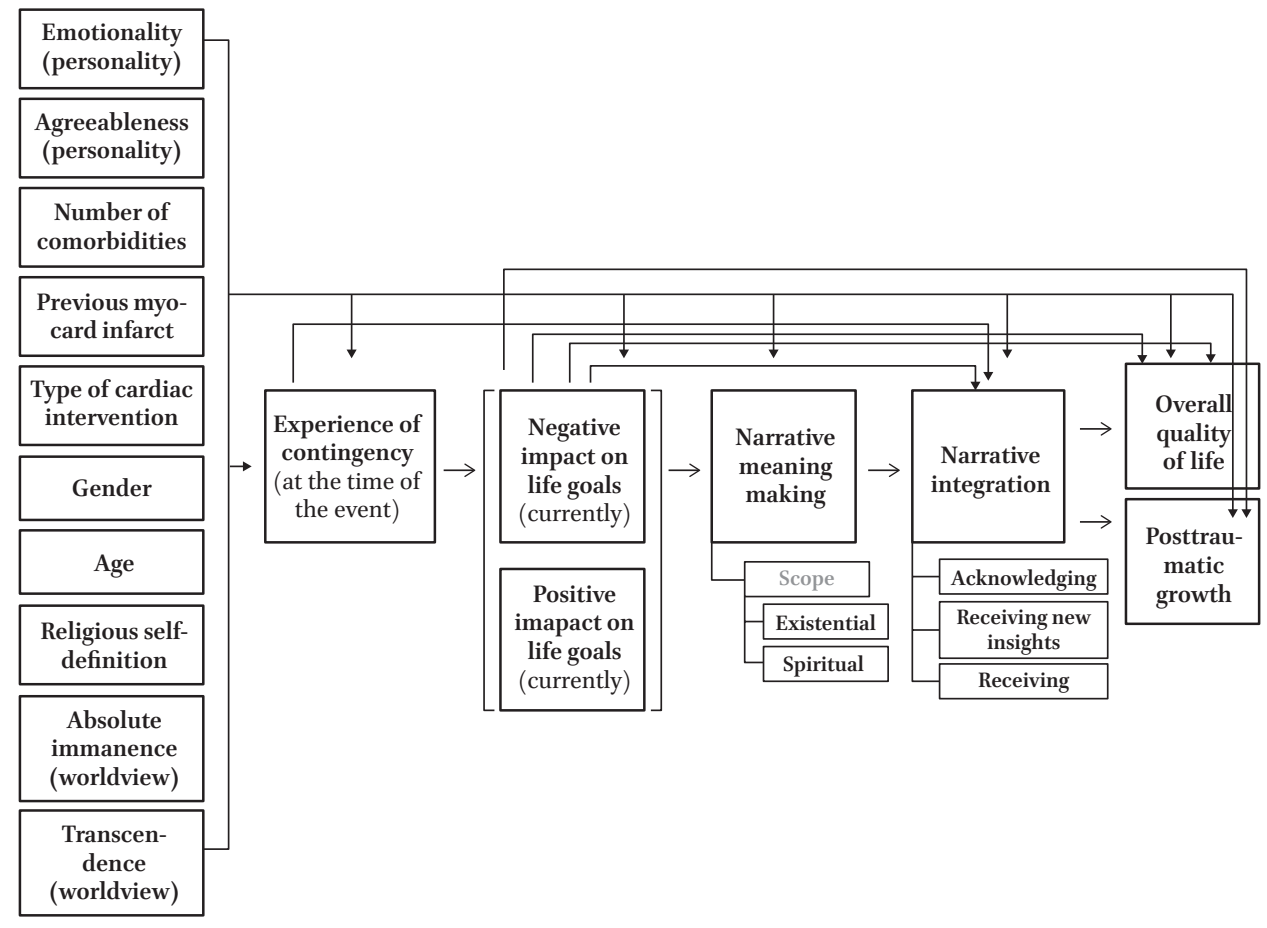

FIGURE 2 Measurement model for mediation analysis

impact of the event on respondents' life goals, and assesses worldview separately. Therefore, the two sub-concepts of 'worldview' ('absolute immanence' and 'transcendence') were considered as background variables, hypothesized to influence the mediating variables. Third, to assess the impact of the life event, the concepts 'life event' and 'ultimate life goals' were combined in the operationalization. Respondents were asked about the impact of the life event on their ultimate life goals, as well as the importance of every ultimate life goal. These scores on both variables were combined into the variable 'weighted impact on ultimate life goals' and then divided into two variables: 'total weighed negative impact on ultimate life goals' and 'total weighed positive impact on ultimate life goals' (in short: 'negative/positive impact'). Fourth, we reversed the order of the 'negative/positive impact' and 'experience of contingency' variables in the hypothesized mediation model. The reason for this is that the RE-LIFE questionnaire assesses the 'experience of contingency' at the time of the event and the current impact of the event on the ultimate life goals. Because of this order in time, we expected the 'experience of contingency' at the time of the diagnosis to have impact on life goals at the time of the assessment.

In addition, 'posttraumatic growth' (PTG), a variable that was added as a second outcome to overall QoL (Hartog et al., forthcoming), was considered 
as a possible dependent variable for mediation analysis. PTG is defined as the experience of positive change resulting from the struggle with challenging life crises (Tedeschi and Calhoun 2004) and was therefore hypothesized to concur with our concept of narrative integration (Hartog et al., forthcoming).

Hypotheses were formulated considering the relationships between the core concepts of our theoretical model, including QoL. First, we expected 'experience of contingency' to influence QoL negatively, with the concepts between them (see Figure 2) functioning as mediators, i.e. accounting fully or partially for the influence of 'experience of contingency'.

Second, more 'experience of contingency' was hypothesized to be associated with more 'negative impact on ultimate life goals' and less 'positive impact on ultimate life goals'. The direction of the influence on 'positive impact' was not certain: because positive impact on life goals can result from a reinterpretation of a negative life event, 'experience of contingency' may also be positively associated with 'positive impact'. In addition, 'experience of contingency' was expected to have a positive influence on both 'existential meaning' and 'spiritual meaning', a positive influence on 'acknowledging' and a negative influence on 'receiving' and 'receiving new insights'. In analogy with 'positive impact', the expected direction of the influence on 'receiving' and 'receiving new insights' is debatable. Indeed, these two modes of narrative integration could also be positively influenced by the experience of contingency at the time of the diagnosis.

Third, considering narrative integration, 'acknowledging' was expected to have a negative influence on QoL, and 'receiving' and 'receiving new insights' a positive influence. Fourth, 'negative impact' was expected to lead to more 'acknowledging' and lower QoL, while 'positive impact was expected to result in less 'acknowledging' and higher levels of QoL. Fifth, 'positive impact' was hypothesized to lead to more, and 'negative impact' to less 'receiving' and 'receiving new insights'.

\section{Methods}

\subsection{Study Design}

The RE-LIFE questionnaire was tested within the context of the IMPACT study on quality of life among people with stable coronary artery disease (CAD) scheduled for elective cardiac intervention. After recruitment, respondents 
completed QoL questionnaires prior to, and two weeks, three months and six months after their intervention. At three and six months, the RE-LIFE was included in the questionnaire set. For the present study, the three-month assessment was used. Sociodemographic information was collected at baseline. Posttraumatic growth and personality were assessed at the three and six-month assessments, respectively. Because the central ethics committee confirmed that the Medical Research Involving Human Subjects Act (wMo) did not apply to our study, further ethical assessment of the study was not required. All patients gave written informed consent.

\subsection{Participants}

Participants were recruited at the cardiology departments of the Amsterdam University Medical Centers (Amsterdam UMC): Academic Medical Center (AMC) and VU Medical Center (VUmc). Inclusion criteria were being scheduled for an elective percutaneous coronary intervention (PCI) or elective coronary artery bypass graft $(\mathrm{CABG})$ at the AMC or VUmc and having at least one confirmed diagnosis of an additional chronic, somatic disease. Exclusion criteria were having psychiatric comorbidities or insufficient command of the Dutch language.

\subsection{RE-LIFE Variables}

Experience of contingency was measured with 5 items, using a 4-point scale ranging from 1 ('did not experience') to 4 ('experienced very strongly').

Negative and positive impact on life goals is a variable resulting from combining two other variables. The first variable is the impact of the event on 15 life goals, assessed with a 7-point scale ranging from 1 ('greatly hinders') to 7 ('greatly helps'). The second variable is the importance of the same 15 life goals, using a 4-point scale ranging from 1 ('not important') to 4 ('very important'). The two variables were combined into a 'weighed total impact', ranging from -12 for greatly hindered very important life goals, to +12 for greatly helped very important life goals. Consequently, this variable was separated into the two variables 'total negative impact' and 'total positive impact' (only the first one met the criteria for mediation analysis). 'Total negative impact' scores range from 1 to 12 , with higher scores indicating more negative impact of the life event on ultimate life goals.

Existential and spiritual meaning were measured with 2 and 3 items respectively, employing a 5-point Likert scale ranging from 1 ('totally disagree') to 5 ('totally agree').

Acknowledging, Receiving new insights and Receiving were measured with 5 , 2 and 2 items respectively, using a 5 -point Likert scale ranging from 1 ('totally disagree') to 5 ('totally agree'). 


\subsection{Outcome Measures ${ }^{3}$}

Overall QoL was assessed with an item from the EORTC Quality of Life Core Questionnaire (EORTC QLQ-C30) (Aaronson et al. 1993). The item assesses respondents' overall QoL during the past week, employing a 7-point response scale ranging from 1 ('very poor') to 7 ('excellent'). This item is also included in the RE-LIFE questionnaire.

Posttraumatic growth was assessed using the Posttraumatic Growth Index (PTGI) (Tedeschi and Calhoun 1996). The questionnaire comprises 21 items and employs a 6-point Likert scale ranging from o ('not') to 5 ('to a very great degree'), reflecting how much positive change was experienced as a result of the respondent's 'crisis'. In our study, the word 'crisis' was changed into 'your heart condition and/or its treatment'. A total PTG I score was calculated, with higher scores indicating more posttraumatic growth (Tedeschi and Calhoun 2004).

\subsection{Background Variables ${ }^{3}$}

Personality: Two personality dimensions, 'emotionality' and 'agreeableness', were assessed with the HEXACO Personality Inventory-Dutch, simplified version (HEXACO-SPI) (De Vries and Born 2013). Both dimensions are assessed with 16 items, using a 5-point Likert scale ranging from 1 ('totally disagree') to 5 ('totally agree'). Mean scores for both dimensions were calculated, with higher scores indicating more emotionality and more agreeableness, respectively.

Worldview: Absolute immanent and Transcendent worldview, in this study considered as background variables, were assessed with 2 and 4 items respectively. A 5-point Likert scale was used, ranging from 1 ('totally disagree') to 5 ('totally agree'). These items are also part of the RE-LIFE questionnaire.

Socio-demographic variables: Participants provided sociodemographic information at baseline, including gender, age and religion. For religion, the response categories of subjective religion (Christian, atheist, Muslim, Buddhist, Jewish and 'other') were aggregated into the categories 'religious', 'nonreligious' and 'other'.

Medical variables: The following medical information was obtained from patients' medical files: the type of intervention received (in descending order of impact: bypass surgery, percutaneous intervention or only cardiac catheterization); occurrence of myocard infarcts in the past; and the number of comorbidities.

\subsection{Selection of Variables for Mediation Analysis}

We conducted a regression-based serial multiple mediation analysis, using the PROCESS-macro in SPSS developed by Hayes (2018a; 2018b). Because of the

3 Previously described in Hartog et al. (forthcoming). 

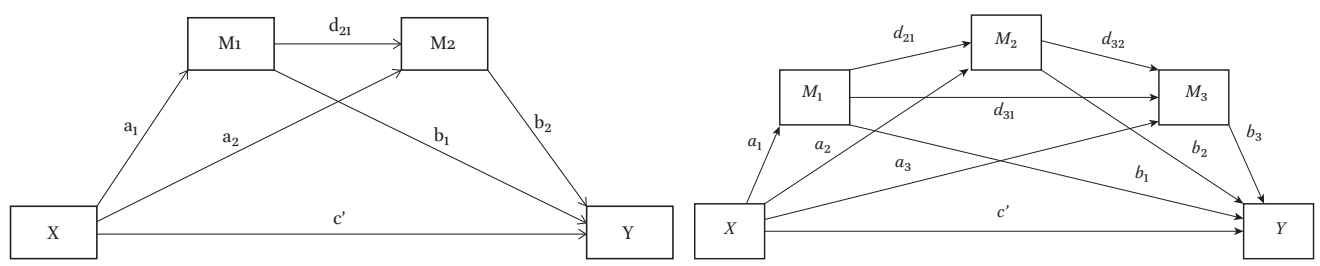

FIGURE 3 Conceptual diagrams of 'Model 6' with two and three mediators in the PROCESS macro $\mathrm{X}=$ dependent variable; $\mathrm{Y}=$ dependent variable; $\mathrm{M}$ = mediator

hypothesized serial mediation in our model, we used 'model 6', which allows for analysing two to four mediators (see Figure 3). As shown in the figure, every mediator consists of one variable, in contrast to our measurement model in which concepts are sometimes divided into more variables, such as negative/ positive impact on life goals and existential/spiritual meaning. This meant that for every 'step' in our measurement model, only one variable could be selected to assess its possible mediating role (e.g. in the case of narrative meaning making, either 'existential' or 'spiritual').

To assess which variables met the criteria for possible mediation, a table with all bivariate correlations including the background variables was inspected (see Appendix). For the independent variables in the mediation models, only the background variables and 'experience of contingency' were considered, and only if they correlated $\geq 0.20$ with at least one of the possible mediators and one of the outcome measures. For the mediators, RE-LIFE variables were considered if they correlated $\geq 0.20$ with one of the background variables as well as with one of the outcome measures. For the dependent variables, the outcome measures were considered as well as the 'narrative integration' variables.

\subsection{Statistical Analyses}

For this study, only complete cases were analysed. All data were assessed to check whether they met the assumptions for regression analysis: homoscedasticity, normality of estimation error, independence of observations, and linearity for all the direct and indirect effects.

After the selection of variables for mediation analysis, regression-based serial mediation analyses were conducted for two different models. The 3.2 version of the PROCESS macro (Hayes 2013) for SPSS (IBM 2014) was used for these analyses. To assess the significance of the indirect effects, bootstrap samples $(\mathrm{N}=5,000)$ were taken to calculate $95 \%$ bias-corrected confidence intervals.

Because the variables in the two mediation models were assessed using different response scales, standardized Beta coefficients and adjusted $\mathrm{R}^{2}$ values 
were calculated to facilitate comparison of the magnitudes of the effects. Results (unstandardized) are in terms of the independent variable: for every 'unit' increase in $\mathrm{X}$, there is an $\mathrm{a}_{1}$ or $\mathrm{a}^{*} \mathrm{~b}$ change in $\mathrm{M}$ or $\mathrm{Y}$. Standardized Beta coefficients are given in terms of standard deviations and thus range between 0 and 1.

To further examine the influence of the independent variable ('experience of contingency'), a Student's t-test was performed to differentiate between respondents with and without an experience of contingency. For this purpose, two categorial variables were created: 'No EoC' (mean scores for 'experience of contingency' 1-2.99 on a 5-point Likert scale) and 'EoC' (mean scores 3-5). Means for the dependent variables 'negative impact', 'existential scope', 'acknowledging' and 'QoL' were calculated for both groups. Based on our theoretical model, we hypothesized that compared to the group without an experience of contingency, respondents with an experience of contingency would show higher mean scores on 'negative impact', existential scope' and 'acknowledging' and lower mean scores on QoL.

\section{$6 \quad$ Results}

\subsection{Participants}

246 participants ( $71 \%$ male) completed the questionnaire, with a mean age of 68 (SD 8.6). The number of complete cases varied per scale (between 218 and 224 cases).

See Table 1 for the characteristics of the participants.

TABLE 1 Participant characteristics

Sample $(\mathrm{N}=\mathbf{2 4 6})$

Age

Median (range)

$69(46-87)$

Mean (SD)

$68(8.7)$

Gender

Female

$71(29 \%)$

Male

$175(71 \%)$

Religion

Religious

Non-religious

$105(43 \%)$

Other (not specified)

$89(36 \%)$

$35(14 \%)$

Missing

$17(7 \%)$ 


\subsection{Selection of Variables for Mediation Analysis}

Based on the correlation table, the bivariate regression coefficients and the theory underlying our model, three possible models of serial mediation were selected, see Figures $4 \mathrm{a}$ and $4 \mathrm{~b}$. Of the background variables, only the personality dimension 'Emotionality' met the criteria for functioning as an independent variable in a mediation model, with QoL as the outcome. Because of our focus on our theoretical model in this article, here we will confine ourselves to the two mediation models in which 'experience of contingency' is the independent variable.

The first hypothesized mediation model (Figure 4a) consists of the core concepts of the theoretical model: 'Experience of contingency' $(\mathrm{X})$ influencing 'Acknowledging' (indicating no narrative integration) $(\mathrm{Y})$ through the

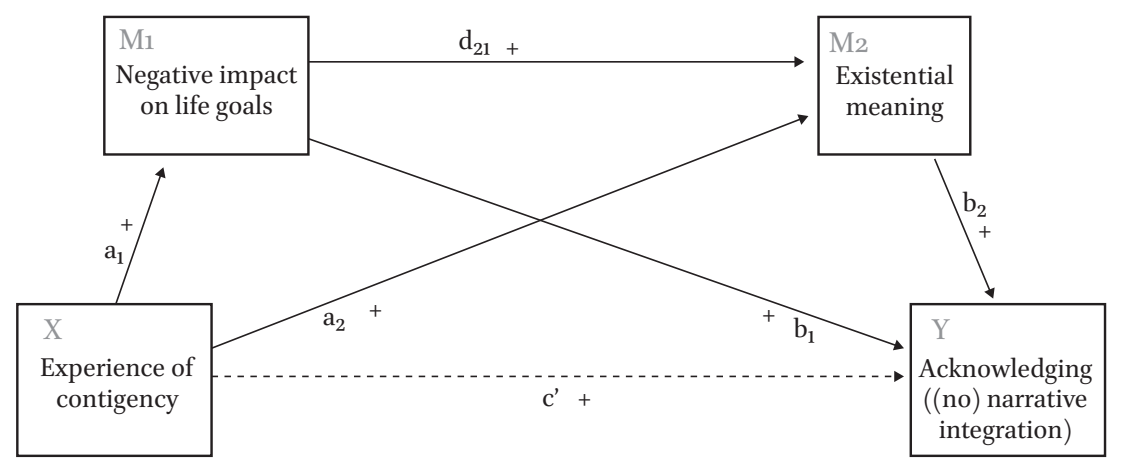

FIGURE 4A Hypothesized mediation model 1

+ = positive effect; - = negative effect; -----> = nonsignificant effect

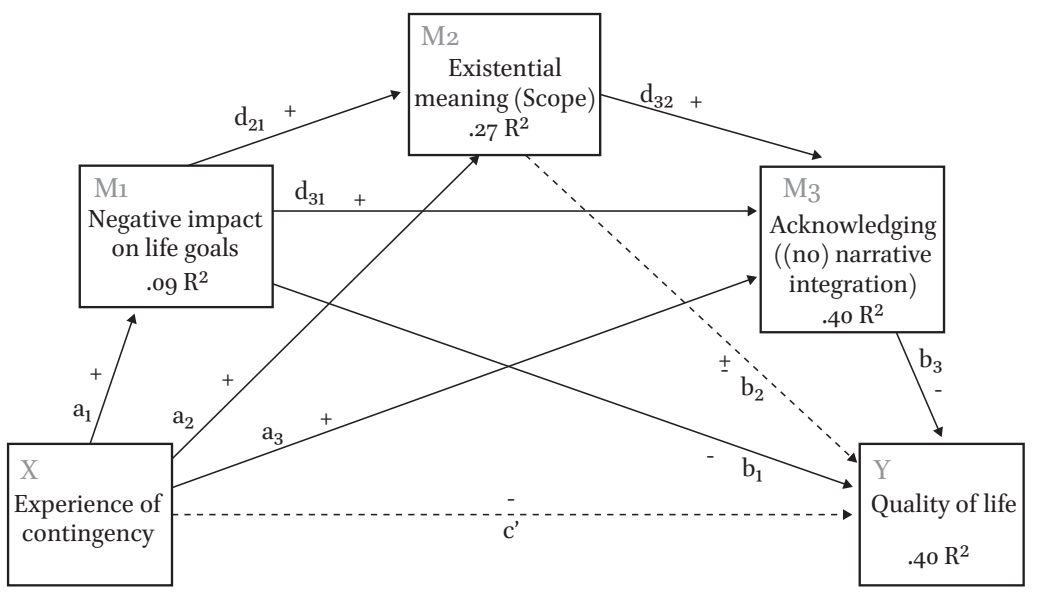

FIGURE 4B Hypothesized mediation model 2

$+=$ positive effect; - = negative effect; -----> = nonsignificant effect 
mediators 'Negative impact' (M1) and 'Existential meaning' (M2). The underlying idea is that the influence of 'experience of contingency' on 'acknowledging' may be partly or fully explained by one or both mediators. Based on the theory underlying our model, we hypothesized all direct and indirect effects to be positive. As for the mediation, we expected the relationship between 'experience of contingency' and 'acknowledging' to be fully mediated by 'negative impact' and 'existential meaning'. Indeed, the 'experience of contingency' at the time of the event could only be expected to lead to more acknowledging (existential struggle) at the present moment if there was currently a negative impact on life goals and an existential meaning of the event. Thus, the direct effect ( $c^{\prime}$ ) was hypothesized to become nonsignificant as a result of adding the two mediators.

The second hypothesized model encompasses this 'core model', adding one variable relevant for the medical context of our study: Quality of life (QoL) as the dependent variable $(\mathrm{Y})$ of the model. Thus, it was hypothesized that 'experience of contingency' would influence QoL, through the mediators 'negative impact', 'existential meaning' and 'acknowledging'. Considering the mediation, in this model we also expected the direct effect (c') to become nonsignificant after adding the three mediators. It was hypothesized that an 'experience of contingency' at the time of the diagnosis would only be detrimental to QoL in the case of current 'negative impact in life goals' and 'acknowledging'.

\subsection{Statistical Analyses}

Inspection of the data showed that all variables met de assumptions for regression-based mediation analysis. See Table 2 for means and standard deviations of the variables in mediation models 1 and 2.

\subsubsection{Mediation Model 1}

Results from the serial mediation analysis with two mediators indicated that the total effect of 'Experience of contingency' on 'Acknowledging' ( $c=$ $.54, \mathrm{p}<.001$ ) could indeed be explained by significant indirect effects through 'Negative impact on life goals' and 'Existential meaning' as well as through both mediators, see Figure 5. Contrary to expectation however, only a partial mediation was found, as the direct effect of 'experience of contingency' on 'acknowledging' remained significant $\left(c^{\prime}=.41, \mathrm{p}<.001\right)$. This means that part of the influence of 'experience of contingency' at the time of the diagnosis on current 'acknowledging' is not explained by the negative impact on life goals and the existential meaning of the event. See Table 3 for all results of the first mediation analysis.

A $95 \%$ bias-corrected confidence interval based on 5,000 bootstrap samples showed that the long-way indirect effect $\left(\mathrm{a}_{1}{ }^{*} \mathrm{~d}_{21}{ }^{*} \mathrm{~b}_{2}=.02\right)$ as well as both 
TABLE 2 Means and standard deviations

Variable

Experience of contingency

Experience of contingency ${ }^{1}$

Impact on life goals

Negative impact ${ }^{2}$

Narrative meaning making

Existential (scope)

Spiritual (scope)

Narrative integration

Acknowledging

Receiving new insights

Receiving

Quality of life

Overall QoL
2.00

0.88

1.67

1.34

2.68

0.88

Mean

SD

$\begin{array}{ll}2.24 & 0.76\end{array}$

$\begin{array}{ll}2.72 & 0.86\end{array}$

$\begin{array}{ll}3.16 & 0.74\end{array}$

$\begin{array}{ll}1.97 & 0.67\end{array}$

$5 \cdot 35 \quad 1.23$

Responses are scored on a 5 -point Likert scale ( $1=$ 'strongly disagree', $5=$ 'strongly agree'), unless stated otherwise with superscript: ${ }^{1}=4$-point scale $(1=$ 'did not experience', $4=$ 'experienced very strongly'). ${ }^{2}=12$-point combined scale $(1=$ very low weighed negative impact on life goals, $12=$ very high weighed negative impact on life goals)

Direct effect $\mathrm{X}$ on $\mathrm{Y}\left(\mathrm{c}^{\prime}\right)=.41$

Total of indirect effects $=.12$

Total effect $\mathrm{X}$ on $\mathrm{Y}(\mathrm{c})=-.54$

Prop. variance explained $\left(.30\right.$ adj. $\left.\mathrm{R}^{2}\right)=30 \%$

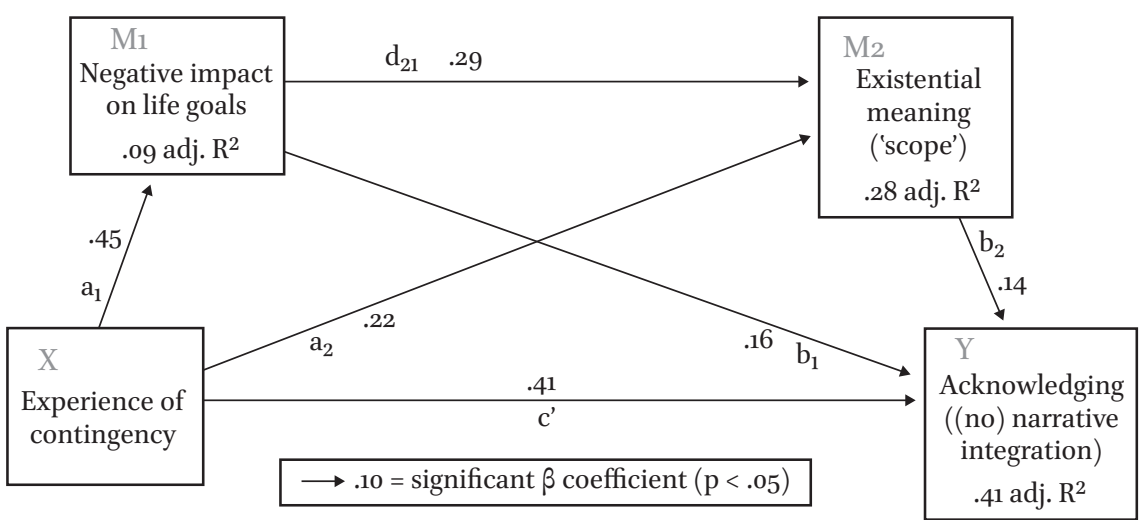

FIGURE 5 Results from mediation analysis - two mediators (Model 1) 
TABLE 3 Results from mediation analysis - two mediators (Model 1)

\begin{tabular}{|c|c|c|c|c|c|c|c|c|}
\hline Path & Direct effects & B & $\beta$ & $95 \% \mathrm{CI}$ & se & $\mathrm{t}$ & $\mathbf{R}$ & Adj. $R^{2}$ \\
\hline$a_{1}$ & $\begin{array}{l}\text { Experience of Contingency } \\
\text { on Negative impact }\end{array}$ & $.45^{* * *}$ & $30^{* * *}$ & $.26-.65$ & .10 & 4.53 & $30^{* * *}$ & $.09^{* * *}$ \\
\hline $\mathrm{a}_{2}$ & $\begin{array}{l}\text { Experience of Contingency } \\
\text { on Existential meaning }\end{array}$ & $.22^{* * *}$ & $.22^{* * *}$ & $.10-.35$ & .06 & $3 \cdot 5^{0}$ & & \\
\hline $\mathrm{d}_{21}$ & $\begin{array}{l}\text { Negative impact on } \\
\text { Existential meaning }\end{array}$ & $.29^{* * *}$ & $.43^{* * *}$ & $.21-.37$ & .04 & 6.95 & $.53^{* * *}$ & $.28^{* * *}$ \\
\hline$b_{1}$ & $\begin{array}{l}\text { Negative impact on } \\
\text { Acknowledging }\end{array}$ & $.16^{* * *}$ & $.26^{* * *}$ & $.09-.24$ & .04 & 4.14 & & \\
\hline$b_{2}$ & $\begin{array}{l}\text { Existential meaning on } \\
\text { Acknowledging }\end{array}$ & $.14^{*}$ & $.15^{*}$ & $.01-.27$ & .06 & 2.36 & & \\
\hline$c^{\prime}$ & $\begin{array}{l}\text { Experience of Contingency } \\
\text { on Acknowledging (direct) }\end{array}$ & $.41^{* * *}$ & $.42^{* * *}$ & $.30-.5^{2}$ & .06 & $7 \cdot 31$ & $.64^{* * *}$ & $.41^{* * *}$ \\
\hline $\begin{array}{l}\text { Path } \\
\text { c }\end{array}$ & $\begin{array}{l}\text { Total effect } \\
\text { Experience of Contingency -> } \\
\text { Acknowledging (total) }\end{array}$ & $\begin{array}{l}\text { B } \\
.54^{* * *}\end{array}$ & $\begin{array}{l}\beta \\
.55^{* * *}\end{array}$ & $\begin{array}{l}95 \% \mathrm{CI} \\
.42-.65\end{array}$ & $\begin{array}{l}\text { se } \\
.06\end{array}$ & $\begin{array}{l}\mathbf{t} \\
9 \cdot 47\end{array}$ & $\begin{array}{l}\mathbf{R} \\
.55^{* * *}\end{array}$ & $\begin{array}{l}\text { Adj. } \mathbf{R}^{2} \\
\cdot 30^{* * *}\end{array}$ \\
\hline
\end{tabular}

\begin{tabular}{llllll}
\hline Path & Indirect effects & B & $\beta$ & 95\%CI & se \\
\hline $\mathrm{a}_{1}{ }^{*} \mathrm{~b}_{1}$ & $\begin{array}{l}\text { Experience of Contingency -> Negative } \\
\text { Impact -> Acknowledging }\end{array}$ & .07 & .08 & $.06-.20$ & .02 \\
$\mathrm{a}_{2}{ }^{*} \mathrm{~b}_{2}$ & $\begin{array}{l}\text { Experience of Contingency -> Existential } \\
\text { meaning - }>\text { Acknowledging }\end{array}$ & .03 & $.00-.07$ & .02 \\
$\mathrm{a}_{1}{ }^{*} \mathrm{~d}_{21}{ }^{*} \mathrm{~b}_{2}$ & $\begin{array}{l}\text { Experience of Contingency -> Negative } \\
\text { impact -> Existential meaning -> }\end{array}$ & .02 & .02 & $.00-.04$ & .01 \\
& $\begin{array}{l}\text { Acknowledging } \\
\text { Total of indirect effects }\end{array}$ & .12 & .13 & $.06-.20$ & .03 \\
\hline
\end{tabular}

\footnotetext{
* $=\mathrm{p}<.05$

$* * \mathrm{p}<.01$

**** $=\mathrm{p}<.001$

$\mathrm{B}=$ regression coefficients

$\beta=$ standardized regression coefficients

se $=$ standard error

Adj. $R^{2}=$ adjusted R-square (standardized)
} 
shortcut-effects $\left(\mathrm{a}_{1}{ }^{*} \mathrm{~b}_{1}=.07, \mathrm{a}_{2}{ }^{*} \mathrm{~b}_{2}=.03\right)$ were entirely above zero. This indicates with $95 \%$ certainty that the indirect effects are indeed positive.

The direct and indirect effects of 'experience of contingency' together explain $30 \%$ of the proportional variance $\left(\mathrm{R}^{2}\right)$ in 'acknowledging'. Combined with the direct effects of the two mediators this explains $41 \%$ of the proportional variance in 'acknowledging'.

\subsubsection{Mediation Model 2}

Serial mediation analysis with three mediators indicates that the total effect of 'experience of contingency' on QoL $(c=-.51, \mathrm{p}<.001)$ is fully mediated by the variables 'negative impact', 'existential meaning' and 'acknowledging', see Figure 6. Indeed, the direct effect of 'experience of contingency' on QoL becomes nonsignificant $\left(c^{\prime}=-.14, \mathrm{p} .=.25\right)$ when the mediators are added.

The 95\% bias-corrected confidence interval based on 5,000 bootstrap samples showed that the total of indirect effects $(-.38)$ as well as five of the seven shortcut-effects through one, two and three mediators, were entirely above zero when holding the other mediators constant. This indicates with $95 \%$ certainty that these indirect effects are indeed negative. As hypothesized, the direct effect of 'existential scope' was shown to be nonsignificant, which means that the mediator 'acknowledging' indeed accounts for the influence of 'existential meaning' on QoL. See Table 4 for all results of the second mediation analysis.

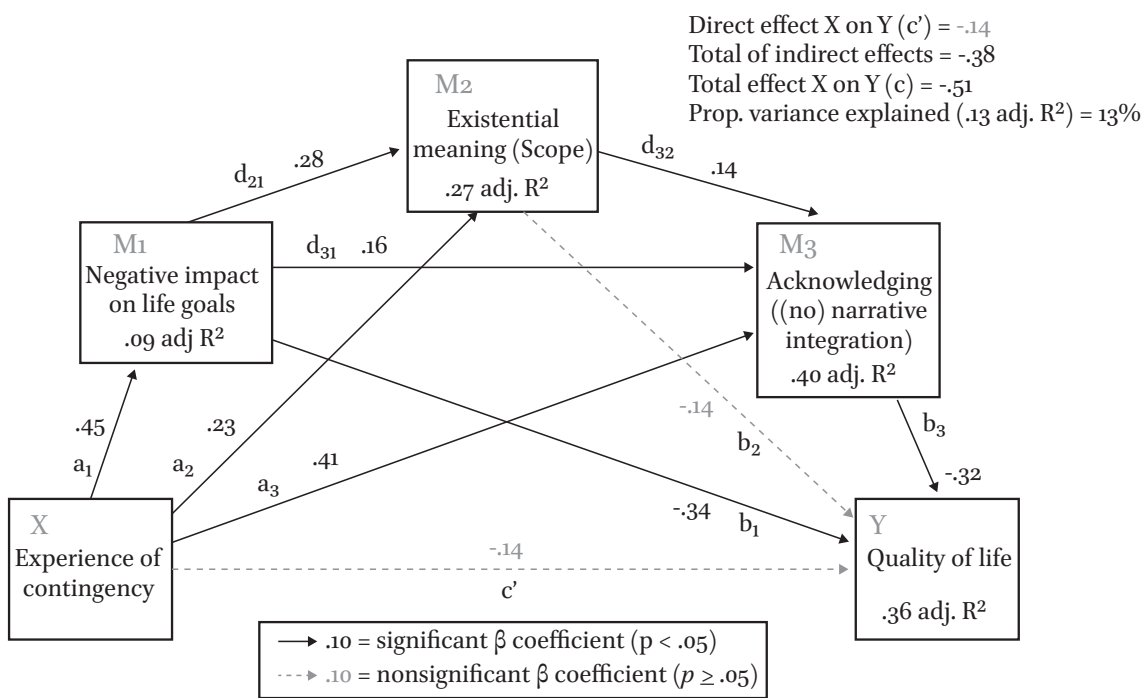

FIGURE 6 Results from mediation analysis-three mediators (model 2) 
TABLE 4 Results from mediation analysis-three mediators (model 2)

\begin{tabular}{|c|c|c|c|c|c|c|c|c|}
\hline Path & Direct effects & B & $\beta$ & $95 \%$ CI & se & $\mathbf{t}$ & $\mathbf{R}$ & Adj. $\mathbf{R}^{2}$ \\
\hline$a_{1}$ & $\begin{array}{l}\text { Experience of } \\
\text { Contingency }->\text { Negative } \\
\text { impact }\end{array}$ & $.46^{* * *}$ & $30^{* * *}$ & $.26-.66$ & .10 & $4.5^{0}$ & $\cdot 30^{* * *}$ & $.09^{* * *}$ \\
\hline$a_{2}$ & $\begin{array}{l}\text { Experience of } \\
\text { Contingency }->\text { Existential } \\
\text { meaning }\end{array}$ & $.23^{* * *}$ & $.22^{* * *}$ & $.10-.35$ & .06 & $3 \cdot 5^{0}$ & & \\
\hline$d_{21}$ & $\begin{array}{l}\text { Negative impact -> } \\
\text { Existential meaning }\end{array}$ & $.28^{* * *}$ & $.42^{* * *}$ & $.18-.38$ & .05 & $5 \cdot 74$ & $\cdot 5^{2^{* * *}}$ & $.27^{* * *}$ \\
\hline$a_{3}$ & $\begin{array}{l}\text { Experience of } \\
\text { Contingency }-> \\
\text { Acknowledging }\end{array}$ & $.41^{* * *}$ & $.42^{* * *}$ & $.29^{-} \cdot 5^{2}$ & .06 & 7.10 & & \\
\hline$d_{31}$ & $\begin{array}{l}\text { Negative impact -> } \\
\text { Acknowledging }\end{array}$ & $.16^{* * *}$ & $.25^{* * *}$ & $.08-.24$ & .04 & 4.40 & & \\
\hline$d_{32}$ & $\begin{array}{l}\text { Existential meaning -> } \\
\text { Acknowledging }\end{array}$ & $.14^{*}$ & $.15^{*}$ & $.02-.26$ & .06 & 2.10 & $.63^{* * *}$ & $.40^{* * *}$ \\
\hline$b_{1}$ & Negative impact -> QoL & $-.34^{* *}$ & $-.37^{* *}$ & $-.54^{--.13}$ & .10 & -3.29 & & \\
\hline$b_{2}$ & $\begin{array}{l}\text { Existential meaning -> } \\
\text { QoL }\end{array}$ & -.14 & -.10 & $-.32-.05$ & .09 & -1.46 & & \\
\hline $\mathrm{b}_{3}$ & Acknowledging -> QoL & $-.32^{* *}$ & $-.23^{* *}$ & $-.53^{--.12}$ & .10 & -3.11 & & \\
\hline$c^{\prime}$ & $\begin{array}{l}\text { Experience of } \\
\text { Contingency -> QoL } \\
\text { (direct) }\end{array}$ & -.14 & -.10 & $-.32-.05$ & .09 & -1.46 & $.62^{* * *}$ & $\cdot 38^{* * *}$ \\
\hline Path & Total effect & B & $\beta$ & $95 \%$ CI & se & $\mathbf{t}$ & $\mathbf{R}$ & Adj. $\mathbf{R}^{2}$ \\
\hline c & $\begin{array}{l}\text { Experience of Contingency } \\
\text { on QoL (total) }\end{array}$ & $-.51^{* * *}$ & $-.37^{* * *}$ & $-.70^{--} .33$ & .09 & $-5 \cdot 59$ & $\cdot 36^{* * *}$ & $.13^{* * *}$ \\
\hline
\end{tabular}

\begin{tabular}{llllll}
\hline Path & Indirect effects & B & $\beta$ & $95 \%$ CI & se \\
\hline $\mathrm{a}_{1}{ }^{*} \mathrm{~b}_{1}$ & $\begin{array}{l}\text { Experience of Contingency }->\text { Negative } \\
\text { impact }->\text { QoL }\end{array}$ & -.15 & -.11 & $-.28--.05$ & .06 \\
$\mathrm{a}_{2}{ }^{*} \mathrm{~b}_{2}$ & $\begin{array}{l}\text { Experience of Contingency }->\text { Existential } \\
\text { meaning }->\text { QoL }\end{array}$ & -.03 & -.02 & $-.08-.02$ & .03
\end{tabular}


TABLE 4 Results from mediation analysis - three mediators (model 2) (cont.)

\begin{tabular}{|c|c|c|c|c|c|}
\hline Path & Indirect effects & B & $\beta$ & $95 \% \mathrm{CI}$ & se \\
\hline$a_{3}{ }^{*} b_{3}$ & $\begin{array}{l}\text { Experience of Contingency -> } \\
\text { Acknowledging -> QoL }\end{array}$ & -.13 & -.09 & $-.23^{--.04}$ & .05 \\
\hline $\mathrm{a}_{1}{ }^{*} \mathrm{~d}_{21}{ }^{*} \mathrm{~b}_{2}$ & $\begin{array}{l}\text { Experience of Contingency }->\text { Negative } \\
\text { impact }->\text { Existential meaning }->\text { QoL }\end{array}$ & -.02 & -.01 & $-.05-.01$ & .02 \\
\hline $\mathrm{a}_{1}{ }^{*} \mathrm{~d}_{31}{ }^{*} \mathrm{~b}_{3}$ & $\begin{array}{l}\text { Experience of Contingency }->\text { Negative } \\
\text { impact }->\text { Acknowledging }->\text { QoL }\end{array}$ & -.02 & -.02 & $-.05^{--.01}$ & .01 \\
\hline $\mathrm{a}_{2}{ }^{*} \mathrm{~d}_{32}{ }^{*} \mathrm{~b}_{3}$ & $\begin{array}{l}\text { Experience of Contingency }->\text { Existential } \\
\text { meaning }->\text { Acknowledging }->\text { QoL }\end{array}$ & -.01 & -.007 & $-.03^{--} .0001$ & .007 \\
\hline $\begin{array}{l}\mathrm{a}_{1}{ }^{*} \mathrm{~d}_{21}{ }^{*} \\
\mathrm{~d}_{32}{ }^{*} \mathrm{~b}_{3}\end{array}$ & $\begin{array}{l}\text { Experience of Contingency -> Negative } \\
\text { impact -> Existential meaning -> } \\
\text { Acknowledging -> QoL }\end{array}$ & -.01 & -.004 & $-.02--.0002$ & .004 \\
\hline- & Total of indirect effects & -.38 & -.27 & $-.54^{--.22}$ & .08 \\
\hline
\end{tabular}

$*=p<.05$

$* *=\mathrm{p}<.01$

$* * * * \mathrm{p}<.001$

Italics $=95 \% \mathrm{CI}$ including zero, i.e. non-significant effect

$\mathrm{B}=$ regression coefficients

$\beta=$ standardized regression coefficients

se $=$ standard error

Adj. $\mathrm{R}^{2}=$ adjusted $\mathrm{R}$-square (standardized)

The direct and indirect effects of 'experience of contingency' together explain $13 \%\left(\mathrm{R}^{2}=.13, \mathrm{p}<.001\right)$ of the proportional variance in QoL. Combined with the direct effects of three mediators, this explains $36 \%$ of the proportional variance in QoL $\left(\mathrm{R}^{2}=.36, \mathrm{p}<.001\right)$.

\subsection{T-test 'Experience of Contingency'}

Table 5 shows the results of the t-test, examining the differences between people with and without an experience of contingency. Although the group reporting an experience of contingency was relatively small ( $N=39,18 \%)$, all differences in means between the two groups were significant. As hypothesized, respondents with an experience of contingency showed higher mean scores on 'negative impact', existential scope' and 'acknowledging' and lower mean scores on QoL. Notably, the largest difference was seen in 'acknowledging' between 'No EoC' $(\mathrm{M}=2.51, \mathrm{SD}=0.73)$ and 'EoC' $(M=3.70, S D=0.73):-1.19$ on a 5 -point scale $(t(215)=-9.09, \mathrm{p}<.000)$. 
TABLE 5 Group differences based on 'experience of contingency'

\begin{tabular}{llrlllll}
\hline & & N & Mean & SD & $\begin{array}{l}\text { Mean } \\
\text { difference }\end{array}$ & t & df \\
& & & & & & \\
\hline \multirow{2}{*}{ Negative impact } & No EoC & 178 & 1.48 & 1.06 & -1.01 & $-3.00^{* *}$ & 42.56 \\
& EoC & 39 & 2.51 & 2.05 & & & \\
Existential scope & No EoC & 182 & 3.20 & 0.86 & .63 & $-4.18^{* * *}$ & 219 \\
& EoC & 39 & 3.83 & 0.86 & & & \\
Acknowledging & No EoC & 180 & 2.51 & 0.73 & -1.19 & $-9.09^{* * *}$ & 215 \\
& EoC & 37 & 3.70 & 0.73 & & & \\
Quality of life & No EoC & 172 & 5.53 & 1.06 & 1.04 & $-3.98^{* * *}$ & 46.27 \\
& EoC & 39 & 4.49 & 1.55 & & & \\
\hline
\end{tabular}

** $\mathrm{p}<.001{ }^{* * *} \mathrm{p}<.000$

$1=12$-point combined scale $(1=$ no weighted negative impact, $12=$ very high weighted negative impact).

${ }^{2}=5$-point scale $(1=$ 'strongly disagree', $5=$ 'strongly agree' $)$

$3=7$-point scale $(1=$ 'very poor', $7=$ 'excellent')

\section{7}

\section{Discussion}

The aim of this study was to examine the relationships between the concepts of the 'Narrative meaning making of life events' model, using data collected with the RE-LIFE questionnaire. After assessing the data to identify possible mediators, two models were assessed with two and three mediators respectively.

\subsection{Model 1}

The first model indicated that respondents who reported a stronger experience of contingency at the time of the diagnosis also reported more 'acknowledging', indicating that the event was not yet integrated into their life stories. While a part of this influence was a direct effect, another part of the effect was the result of influences of 'experience of contingency' on the two mediators, and their influences on the outcome 'acknowledging'. These results support our theoretical assumption that an experience of contingency evokes a process of narrative meaning making. However, our hypothesis that this would lead to a certain degree of narrative integration could not be confirmed. Indeed, in our sample, the variables 'receiving new insights' and 'receiving', indicating narrative integration, did not meet the criteria to function as mediators or dependent variables. This could be due to the fact that only a small part $(18 \%)$ of the 
respondents reported an 'experience of contingency'. Apparently, the life event of being diagnosed with a heart condition did not lead to a crisis of meaning in the majority of respondents, and therefore did not necessitate reinterpretation and narrative integration.

Looking at the standardized coefficients, which allow for comparison, the total of indirect effects accounted for by the mediators is relatively small. Thus, in this model, the effect of 'experience of contingency' on 'acknowledging' is mainly a direct effect. As we hypothesized a full mediation, this is contrary to expectation. Apparently, a stronger experience of contingency at the time of the diagnoses may lead to current struggles and existential questions, regardless of the current negative impact on life goals and the scope of the meaning. This indicates that the current negative impact of the event on life goals plays a smaller role in people's struggle to integrate the event than we hypothesized. In future use of the RE-LIFE questionnaire, the impact on life goals at the time of the event could be assessed to examine its influence on the experience of contingency and consequently on acknowledging.

However, the fact that all effects are significant and positive can still be seen as an indication for the validity of the theoretical model. 'Experience of contingency' shows a relatively large direct effect on 'acknowledging'. In addition, $30 \%$ of the proportional variance of 'acknowledging' is explained by 'experience of contingency' (including the indirect effects) and $41 \%$ including the direct effects of the mediators. These are interesting results in themselves, as these two concepts are of central importance in the model. They indicate that the experience of contingency, associated with the confrontation with 'existential givens' that falling ill often implies, plays an important role in the process of meaning making that follows.

\section{2 $\quad$ Model 2}

The second model showed that more experience of contingency at the time of the diagnosis leads to a lower quality of life at the time of the assessment. In addition, as hypothesized, the effect turned out to be fully explained by indirect effects through the mediators. This means that it is not the experience of contingency at the time of the diagnosis as such that influences the quality of life experienced at the time of the assessment. This influence is only significant for respondents whose experience of contingency led to more negative impact on life goals, more existential meaning of the event, and more acknowledging (the struggle indicating no narrative integration), which is detrimental to the experienced quality of life. These results support our theoretical assumption that as a 'crisis of meaning', an experience of contingency evokes a process in which people struggle to come to terms with the event in the context of their 
life narratives. However, to confirm this assumption, more research is needed among respondents who predominantly report an experience of contingency.

The fact that $13 \%$ of the proportional variance in QoL is explained by 'experience of contingency' (including indirect effects) and $40 \%$ by the whole model, indicates that indeed, QoL is also influenced by other variables than the concepts of our model. However, considering that people's QoL is influenced by a myriad of variables in many domains of their lives, the explanatory power of our model can be considered quite satisfactory. It can be concluded that narrative meaning making and integration play a significant role in people's self-evaluations of their quality of life. These results indicate that indeed, complementary to psychological variables such as coping styles, narrative meaning making and integration are important in our understanding of the QoL people experience. The results of the t-test support this conclusion, as they showed that people with an experience of contingency reported significantly lower levels of QoL than people without an experience of contingency.

\subsection{Clinical Relevance}

Our results show that experiences of contingency lead to a struggle to integrate the event into one's life story in a meaningful way, reducing quality of life. Therefore, our suggestion for psychological or spiritual counselling and psychotherapy would be to discuss the existential issues that clients raise, including the incomprehensibility of the event. In some psychotherapeutic approaches, meaning-centred topics are not explicated because discussing these is seen as an intellectual defence mechanism that shifts away from the 'real problems' (Vos 2017). However, people who seek help after being confronted with a serious illness or other disruptive life events often want to discuss the existential questions evoked by this confrontation. Nowadays, meaning is increasingly considered clinically relevant, and studies show that clients define recovery in the context of mental health problems as building a meaningful life (Andresen et al. 2011). Research shows that existential therapies, especially the types using a meaning-centred approach, seem beneficial for clients in reducing psychopathology and increasing meaning, purpose in life (Vos et al. 2015), quality of life (Kruizinga et al. 2016) and posttraumatic growth (Vos 2017). The relationship between the latter and narrative integration may be worthwhile to investigate further. Previous analysis of data collected with the RE-LIFE questionnaire indicated that all three 'narrative integration' variables ('acknowledging', 'receiving new insights' and 'receiving') positively correlated with posttraumatic growth, while 'acknowledging' negatively correlated with overall QoL (Hartog et al., forthcoming). 
As stated in the introduction, our approach converges with the theoretical foundations of existential-psychotherapeutic approaches. While most existential therapies share a pragmatic-phenomenological approach to meaning (Vos 2017), several 'schools' can be distinguished. They predominantly focus on either 'meaning in life' (e.g. meaning-centred / logotherapy, based on the works of Frankl), or on facing the existential givens of life, such as mortality and meaninglessness (e.g. existential-humanistic approaches, rooted in the works of Yalom). Our approach is in line with recent attempts to integrate these two approaches, while simultaneously integrating psychology, philosophy, psychiatry and theology (Vos 2015). In our emphasis on the experience of contingency, the confrontation with existential givens and the boundaries of our comprehension are explicated together with shattered meanings and conflicts with life goals that are of ultimate concern. The concept of narrative integration implies the duality of searching for meaning in the face of these existential givens. Therapies addressing contingency may help people in constructing narratives while being aware of the contingency of the world, also described as 'creative contingency' (Joas 2014). Integrating disruptive life events into one's life narrative implies giving them a meaningful place and realizing what is of ultimate meaning in life, while remaining open to other possible meanings and the contingency of life in general.

\subsection{Limitations}

Several limitations in this study should be acknowledged. First, the original theoretical model was adjusted to enable mediation analysis in PROCESS, using the RE-LIFE data. As a result, the model could not be validated in its entirety, nor could the original sequence of the concepts be followed (e.g. 'impact on life goals' at the time of the event influencing 'experience of contingency'). An important consequence is that we cannot draw conclusions on narrative integration in the sense of 'receiving' and 'receiving new insights', but only on the absence of narrative integration ('acknowledging'). Depending on the aims, future empirical studies may use adapted versions of the RE-LIFE questionnaire. For example, the impact of the life event on life goals at the time of the diagnosis (instead of at the time of the assessment) may be assessed. The RE-LIFE may also be administered shortly after a diagnosis or other life event, rather than in anticipation of a medical intervention. In addition, as described previously (Hartog et al., forthcoming), some of the RE-LIFE item categories, such as the 'worldview' categories, may benefit from revisions. As a result, they may also qualify to function as independent variables, mediators or moderators in the mediation models. 
Second, our specific study population (heart patients, predominantly males aged between 60 and 70 ) limits the generalizability of the results to other patient or general populations. In addition, as mentioned above, being diagnosed with stable coronary artery disease may not have been a major disruptive event for all respondents. Therefore, the life event may not have led to an experience of contingency in all cases. This assumption is supported by the t-test as well as by the mean of the scores on this scale: 2.00 (SD 0.88), reflecting the 'experienced somewhat' response option in the questionnaire. In addition, mean scores for 'negative impact on life goals' are also low ( 1.67 on a scale ranging from 1 to 12). It is conceivable that the results of our mediation analyses would have been different if a more disruptive life event had been assessed, such as bereavement or being diagnosed with a terminal disease. Indeed, especially events that confront people with the 'existential givens' in life leave people empty-handed when it comes to making meaning of the event. Without such a crisis of meaning, people's framework of interpretation may not be opened up to allow new insights and possibilities.

Third, the observational design of our study, with data collection at one time point, does not allow conclusions about causality. For example, instead of 'acknowledging' influencing QoL, the association between the two could also be interpreted the other way around. It could be argued that a lower QoL, impacted by the disease, the intervention or other circumstances, leads to more struggle and existential questions. Therefore, although the hypothesized nature and directions of the relationships between the concepts are derived from the theories underlying our model, their sequence cannot be confirmed. It thus remains possible that alternate models may offer the same degree of explanation of the data.

Fourth, a relatively large number of variables was assessed and selected for our mediation models, given the size of our sample. This reduces the statistical power of the mediation analyses. Therefore, the results need to be interpreted with caution and confirmed in future, well-powered studies.

\subsection{Conclusion}

In conclusion, serial mediation analyses using the data collected with the RE-LIFE questionnaire indicate that 'experience of contingency', 'negative impact on life goals', 'existential meaning' and 'acknowledging' significantly influence people's self-evaluation of their quality of life. However, it is not the experience of contingency at the time of the diagnosis as such that influences the quality of life experienced at the time of the assessment, but its influence through 'negative impact on life goals', 'existential meaning' and 'acknowledging'. 


\section{Appendix 1-Correlations between All Variables}

\begin{tabular}{|c|c|c|c|c|c|c|c|}
\hline & P-Emo & P-Agree & W-Imm & W-Trans & QoL & PTG & EoC \\
\hline Gender $^{3}$ &, $187^{* *}$ &, $168 *$ &, $215^{* *}$ & , 082 & , 107 & 108 &, 032 \\
\hline Age $^{1}$ & , 449 & , 050 &,- 040 &, $166^{*}$ & ,027 &,- 068 &,$- 226 * *$ \\
\hline $\mathrm{Edu}^{2}$ &,- 110 & ,027 &,$- 174^{*}$ & , 026 &, $196^{*}$ &,- 081 &,- 053 \\
\hline $\mathrm{Rel}^{3}$ &, 154 & , 121 &, $35^{2 * *}$ &, $484^{* *}$ &, 056 &, 112 &, $142^{*}$ \\
\hline Comorb $^{1}$ & ,o62 &, 085 & , 047 & , 010 &,- 003 &,- 049 &, $140^{*}$ \\
\hline PrevMI 3 & , 049 & , 029 &, 042 & ,019 & ,og6 & ,o82 & ,004 \\
\hline PrevInt ${ }^{3}$ & ,026 & ,o93 & ,027 & ,o96 &, $177^{* *}$ & ,055 &, 121 \\
\hline Int.type $^{2}$ &, $138^{*}$ & , 030 &,- 018 &,- 010 & ,028 & ,012 & ,o81 \\
\hline P-Emo ${ }^{1}$ & &,- 019 &,- 115 &, $143^{*}$ &,$- 35^{* * *}$ &, $215^{* *}$ &, $376^{* *}$ \\
\hline P-Agree ${ }^{1}$ & & &,$- 179^{* *}$ &, $181^{* *}$ & ,o64 &,- 106 &,- 094 \\
\hline $\mathrm{W}-\mathrm{Imm}^{1}$ & & & &,$- 408^{* *}$ &,- 008 &, 071 & ,o69 \\
\hline W-Trans ${ }^{1}$ & & & & &, $137^{*}$ &, $210^{* *}$ & ,026 \\
\hline QoL ${ }^{1}$ & & & & & & ,037 &,$- 340^{* *}$ \\
\hline $\mathrm{PTG}^{1}$ & & & & & & &, $223^{* *}$ \\
\hline \multicolumn{8}{|l|}{$\mathrm{EoC}^{1}$} \\
\hline \multicolumn{8}{|l|}{ Spir ${ }^{1}$} \\
\hline \multicolumn{8}{|l|}{ Exist $^{1}$} \\
\hline \multicolumn{8}{|l|}{ NI-Ack ${ }^{1}$} \\
\hline \multicolumn{8}{|l|}{ NI-RecNI ${ }^{1}$} \\
\hline \multicolumn{8}{|l|}{ NI-Rec ${ }^{1}$} \\
\hline \multicolumn{8}{|l|}{ NegImp ${ }^{1}$} \\
\hline \multicolumn{8}{|c|}{$\begin{array}{l}{ }^{1}=\text { Pearson's correlation coefficients ' } r \text { ' (variables both at interval, ratio or scale level) } \\
2=\text { Spearman's correlation coefficients 'rho' (variables at the ordinal x interval, ratio or scale } \\
\quad \text { level) } \\
{ }^{3}=\text { Eta }(\eta) \text { (dichotomous or nominal variables x variables at the interval, ratio or scale level) } \\
{ }^{*} \text { Correlation is significant at the } 0.05 \text { level (2-tailed) } \\
{ }^{* *} \text { Correlation is significant at the } 0.01 \text { level (2-tailed). } \\
\text { P-Emo = Emotionality (personality) } \\
\text { P-Agree = Agreeableness (personality) } \\
\text { W-Imm = Absolute immanence (worldview) } \\
\text { W-Trans = Transcendence (worldview) }\end{array}$} \\
\hline
\end{tabular}




\begin{tabular}{|c|c|c|c|c|c|c|}
\hline Spir & Exist & NI-Ack & NI-RecNI & NI-Rec & Neg-Imp & Pos-Imp \\
\hline , 109 &, 112 & ,009 & ,128 & ,042 & ,o62 & ,o62 \\
\hline,- 096 &,- 124 &,$- 261 * *$ &,- 094 & , o35 &,$- 155^{*}$ & , 085 \\
\hline,- 060 & ,003 &,$- 180^{*}$ &,- 024 & ,o64 &,$- 128 * *$ &,- 101 \\
\hline , 148 &, $182^{*}$ & ,095 & ,052 &, 151 &, $181 *$ &, 127 \\
\hline,- 020 & , 000 & ,122 &,- 031 &,$- 137^{*}$ & , 084 &,- 034 \\
\hline ,026 & , o81 & , 016 & ,127 & ,og6 & ,o36 & ,025 \\
\hline ,ogo & ,og6 & ,001 & ,010 & ,028 & ,095 & ,092 \\
\hline ,o81 &,- 035 &,- 042 &,$- 177^{* *}$ &,- 041 &,- 018 & ,040 \\
\hline, $310^{* *}$ &, $197^{* * *}$ &, $35^{8 * *}$ & ,055 &,- 065 &, $261^{* *}$ &,- 051 \\
\hline,- 005 &,- 064 &,- 054 &,- 008 & ,024 &,$- 207^{* *}$ & ,099 \\
\hline,$- 199^{* *}$ & ,049 &, $164^{*}$ & ,017 &,- 110 & ,023 & ,oo6 \\
\hline, $387^{* *}$ &,$- 257^{* *}$ &,- 014 &, $149^{*}$ &, $165^{*}$ &,$- 209^{* *}$ & $317^{* *}$ \\
\hline,$- 181^{* *}$ &,$- 405^{* *}$ &,$- 46 o^{* *}$ &, 014 & , 095 &,$- 532^{* *}$ &, $241^{* *}$ \\
\hline ,138 &,- 121 &, $244^{* *}$ &, $195^{* * *}$ &, $237^{* *}$ &,- 104 &, $378^{* * *}$ \\
\hline \multirow[t]{7}{*}{, $270^{* *}$} & $320 * *$ &, $545^{* *}$ &, $192^{* *}$ &,- 075 &, $312^{* *}$ & ,o63 \\
\hline & ,023 & $35^{* * *}$ &, $190^{* *}$ &, $319^{* *}$ & , 098 & ,020 \\
\hline & &, $410^{* *}$ &,- 114 &,$- 296 * *$ &, $481^{* *}$ &,$- 263^{* *}$ \\
\hline & & &, $264^{* *}$ & ,o66 &, $444^{* *}$ &,- 109 \\
\hline & & & &, $240^{* *}$ &,- 105 &, $345^{* *}$ \\
\hline & & & & &,$- 227^{* *}$ & ,111 \\
\hline & & & & & &,$- 283^{* *}$ \\
\hline
\end{tabular}

QoL $=$ Overall quality of life

PTG $=$ Posttraumatic growth

EoC $=$ Experience of contingency

Spir $=$ Spiritual

Exist $=$ Existential

NI-Ack = Acknowledging (narrative integration)

NI-RecNI $=$ Receiving new insights (narrative integration)

NI-Rec $=$ Receiving (narrative integration)

Neg-Imp $=$ Negative impact on life goals

Pos-Imp = Positive impact on life goals 


\section{References}

Aaronson, N.K., S. Ahmedzai, B. Bergman, M. Bullinger, A. Cull, N.J. Duez, A. Filiberti, H. Flechtner, S.B. Fleishman and J.C. de Haes (1993). The European Organization for Research and Treatment of Cancer QLQ-C30: a quality-of-life instrument for use in international clinical trials in oncology. Journal of the national cancer institute $85(5), 365-376$.

Andresen, R., L.G. Oades and P. Caputi (2011). Psychological recovery: Beyond mental illness. John Wiley \& Sons.

Baumeister, R.F. (1991). Meanings of life. New York, Guilford Press.

Baumeister, R.F. and K.D. Vohs (2003). Self-regulation and the executive function of the self. In: M.R. Leary and J.P. Tangney (eds.). Handbook of self and identity, pp. 197-217. New York, The Guilford Press.

Bolmsjö, I. (2001). Existential issues in palliative care: interviews of patients with amyotrophic lateral sclerosis. Journal of palliative medicine 4(4), 499-505.

Bucher, A.A. (2014). Psychologie der Spiritualität. Ein Handbuch. Weinheim, Beltz.

Bury, M. (1982). Chronic illness as biographical disruption. Sociology of health \& illness 4(2), 167-182.

Dalferth, I.U. and P. Stoellger (200o). Religion als Kontingenzkultur und die Kontingenz Gottes. In: I.U. Dalferth and P. Stoellger (eds.) Vernunft, Kontingenz und Gott. Konstellationen eines offenen Problems. Tübingen, Mohr Siebeck, 1-44.

De Vries, R.E. and M.P. Born (2013). De Vereenvoudigde HEXACO Persoonlijkheidsvragenlijst en een additioneel interstitieel Proactiviteitsfacet. Gedrag \& Organisatie 26(2), 223-245.

Emmons, R.A. (1999). The psychology of ultimate concerns: Motivation and spirituality in personality. New York, Guilford Press.

Fife, R.B. (2002). Are existential questions the norm for terminally ill patients? Journal of palliative medicine $5(6), 815-817$.

Frankl, V.E. (1962). Man's Search for Meaning: An Introduction to Logotherapy. Boston, Beacon Press.

Frankl, V.E. (1986). The doctor and the soul: From psychotherapy to logotherapy. London, Vintage.

Frankl, V.E. (1988). The will to meaning: Foundations and applications of logotherapy. New York, Penguin.

Frijda, N.H. (2007). The laws of emotion. New Jersey, Lawrence Erlbaum Associates Publishers.

Geertz, C. and M. Banton (1966). Religion as a cultural system. In: M. Banton (ed.) Anthropological Approaches to the Study of Religion, pp. 1-46. London, Tavistock Publications. 
Hartog, I., M. Scherer-Rath, R. Kruizinga, J. Netjes, J. Henriques, P. Nieuwkerk, M. Sprangers and H. van Laarhoven (2017). Narrative meaning making and integration: Toward a better understanding of the way falling ill influences quality of life. Journal of health psychology, 1-17.

Hartog, I.D., T.H. Oreel, M. Scherer-Rath, J.E. Netjes, A.B.A. Vonk, J.S. Lemkes, J.P.S. Henriques, M.A.G. Sprangers, H.W.M. van Laarhoven and P.T. Nieuwkerk (forthcoming). Assessing narrative meaning making and integration of falling ill: psychometric properties of the Reconstruction of Life Events Questionnaire (RE-LIFE).

Hayes, A.F. (2013). Model templates for PROCESS for SPSS and SAS. https://process macro.org/download.html.

Hayes, A.F. (2018a). Introduction to mediation, moderation, and conditional process analysis: A regression-based approach (Second Edition). New York: Guilford Press.

Hayes, A.F. (2018b). Partial, conditional, and moderated moderated mediation: Quantification, inference, and interpretation. Communication Monographs 85(1), 4-40.

IBM Corporation (2014). SPSS Statistics Version 23.0 (for Windows) [computer program], Iвм Corporation Armonk, NY.

Janoff-Bulman, R. (2010). Shattered assumptions: Towards a new psychology of trauma. New York, Simon and Schuster.

Jaspers, K. (1925). Psychologie der Weltanschauungen. Tübingen, Max Niemeyer Verlag. Joas, H. (2014). Faith as an option: Possible futures for Christianity. Stanford, Stanford University Press.

Kraft, C.H. (2008). Worldview for Christian witness. Pasadena, William Carey Library.

Kruizinga, R., I.D. Hartog, M. Jacobs, J.G. Daams, M. Scherer-Rath, J.B.A.M. Schilderman, M.A.G. Sprangers and H.W.M. van Laarhoven (2016). The effect of spiritual interventions addressing existential themes using a narrative approach on quality of life of cancer patients: a systematic review and meta-analysis. Psycho-Oncology 25(3), 253-265.

Kruizinga, R., I.D. Hartog, M. Scherer-Rath, J.B.A.M. Schilderman and H.W.M. van Laarhoven (2017). Modes of relating to contingency: an exploration of experiences in advanced cancer patients. Palliative \& Supportive Care 15(4), 444-453.

Luhmann, N. (1995). Social systems. Stanford, Stanford University Press.

Makropoulos, M. (1997). Modernität und Kontingenz. München, Fink.

Park, C.L. (2010). Making sense of the meaning literature: an integrative review of meaning making and its effects on adjustment to stressful life events. Psychological bulletin 136(2), 257-301.

Park, C.L. (2013). The meaning making model: A framework for understanding meaning, spirituality, and stress-related growth in health psychology. The European Health Psychologist 15(2), 40-47. 
Ricoeur, P. (1995). Oneself as another. Chicago, University of Chicago Press.

Scherer-Rath, M. (2013). Narrative reconstruction as creative contingency. In: R.R. Ganzevoort, M. de Haardt and M. Scherer-Rath (eds.). Religious Stories We live By. Narrative Approaches in Theology and Religious Studies, pp. 131-142. Leiden, Brill. Scherer-Rath, M. (2016). Kontingenz als Lebensbaustein. Narrative Rekonstruktion der Interpretation von Kontingenzerfahrungen. In: C. Höger and S. Arzt (eds.) Empirische Religionspädagogik und Praktischen Theologie, pp. 170-181. Freiburg \& Salzburg.

Schnell, T. (2009). The Sources of Meaning and Meaning in Life Questionnaire (SoMe): Relations to demographics and well-being. The Journal of Positive Psychology 4(6), 483-499.

Schnell, T. and W.J. Keenan (2011). Meaning-making in an atheist world. Archive for the Psychology of Religion 33(1), 55-78.

Strawson, G. (2015). Against narrativity. Narrative, Philosophy and Life. New York, Springer, 11-31.

Tedeschi, R.G. and L.G. Calhoun (1996). The Posttraumatic Growth Inventory: Measuring the positive legacy of trauma. Journal of traumatic stress 9(3), 455-471.

Tedeschi, R.G. and L.G. Calhoun (2004). Posttraumatic growth: Conceptual foundations and empirical evidence. Psychological inquiry 15(1), 1-18.

Tillich, P. (1963). Christianity and the Encounter of the World Religions. New York, Columbia University Press.

Van Bruggen, V., J. Vos, E.T. Bohlmeijer and G. Glas (2013). Over de plaats van existentiële thema's in cognitieve gedragstherapie. Gedragstherapie 46, 119-134.

Vos, J. (2015). Meaning and existential givens in the lives of cancer patients: A philosophical perspective on psycho-oncology. Palliative \& supportive care 13(4), 885-900.

Vos, J. (2017). Meaning in life: An evidence-based handbook for practitioners. London, Macmillan International Higher Education.

Vos, J., M. Craig and M. Cooper (2015). Existential therapies: A meta-analysis of their effects on psychological outcomes. Journal of consulting and clinical psychology 83(1), 115-128.

World Health Organization (1997). WHOQOL: measuring quality of life. Geneva, World Health Organization.

Wuchterl, K. (2011). Kontingenz oder das Andere der Vernunft: zum Verhältnis von Philosophie, Naturwissenschaft und Religion. Stuttgart, Franz Steiner Verlag.

Wuchterl, K. (2019). Religious-philosophical Contingency and Empirical Theology. Journal of Empirical Theology 32(2), 169-187.

Yalom, I.D. (1980). Existential psychotherapy. New York, Basic Books. 